\title{
List of Mushrooms found in Dhikura Village and its Adjoining Rotepakho Community Forest in Arghakhanchi District, Central Nepal
}

\author{
Rajendra Acharya* \\ National Herbarium and Plant Laboratories (KATH), Godawari, Lalitpur, Nepal \\ *Corresponding Author \\ acharya.raj2010@gmail.com
}

\begin{abstract}
The study was carried out for higher fungi, especially mushrooms, found in Dhikura village and its adjoining Rotepakho community forest, Arghakhanchi district, Central Nepal from October 25 to 26, 2014. A total of 33 species, including both Ascomycetes ( 3 species) and Basidiomycetes ( 30 species) fungi were collected from the study area. The documented Ascomycetes species were from three orders belonging to three families and three genera, whereas Basidiomycetes species were from eight orders belonging to 17 families and 26 genera. Polyporales were found to be the dominant order in the study area, with 11 species followed by Agaricales (6 species) and Boletales, Hymenochaetales, and Russullales (3 species). Similarly, Polyporaceae was found to be the dominant family represented by nine species, Hymenochaetaceae ( 3 species), and followed equally by Exobasidiaceae, Sclerodermataceae, and Steriaceae ( 2 species). Litsea monopetala was found to be the primary host plant for three different mushroom species (including one Ascomycetes and two Basidiomycetes species) followed by Shorea robusta, Grewia asiatica, Mangifera indica, Machillus odoratissima, Terminalia bellirica, Wendlandia coriacea and Terminalia chebula (2 Basidiomycetes species).
\end{abstract}

\section{Keywords}

Central Nepal, Ascomycetes, Basidiomycetes, mycodiversity

\section{Introduction}

Nepal, a well-famed country for mycodiversity, with its wide range in ecological conditions from the tropical Terai to the permanent snow at the highest elevation, has played an exciting role in the distribution of diverse mycofloral components (Adhikari 1994-95, 2000, 2009, 2014c). Till now, one monotypic and 35 endemic species of mushroom have been described from Nepal. So far, about 1,271 mushroom species have been recorded from Nepal (Adhikari 2014a). Among these, about 147 species are said to be edible (Adhikari 2014b; Adhikari 2014a), while 100 species are poisonous, and 73 species have medicinal values (Adhikari 2014a). The Nepalese microflora is under the process of exploration since the work of Lloyd (1808) and Berkely (1838), but still, several parts of Nepal await their exploration, investigation, study, and publication (Adhikari, 1999; 2000;
2009). The book entitled "Mushrooms of Nepal" (Adhikari 2014a) provides a compilation of the literature and historical account of mycological explorations in Nepal.

Intense mycological exploration and investigation have been carried out in Central Nepal as compared to eastern and western regions of Nepal (Adhikari 1999; Adhikari 2000; Adhikari $\&$ Bhattarai 2014). The present study was carried out to determine the higher fungi prevailing in Arghakhanchi district (central Nepal).

\section{Materials and Method}

Study area: Arghakhanchi district is one of the hilly districts of the Lumbini zone in Central Nepal. It has unique physiography. Sixty-eight percent of the district lies in the Mahabharat range and the rest in the Siwalik hills. It is situated between $27^{\circ} 45^{\prime}-28^{\circ} 26^{\prime} \mathrm{N}$ latitude and $84^{\circ} 45^{\prime}-83^{\circ} 23^{\prime} \mathrm{E}$ 
longitude. It covers an area of 1,193 sq. Km. It is surrounded by Palpa district in the east, Pyuthan and Dang on the west, Gulmi on the north, and Terai's districts, Kapilvastu and Rupandehi, on the south. The elevation of the district varies from 305 to $2,575 \mathrm{msl}$, and about $40 \%$ of the total area is covered by forest (Bhusal et al., 2013). The forest is composed of mixed pine mainly dominated by Pinus roxburghii with its associated species like Schima wallichii, Wendlandia coriacea, Castanopsis indica, Diospyros lancifolia, Woodfordia fruticosa, Lyonia ovalifolia, Shorea robusta, Grewia asiatica, Mangifera indica, Terminalia bellirica, Wedlandia coriacea, (covering an area of about 47 hectares where people of this region depend on this forest mainly for the fulfillment of their daily subsistence requirements of fuelwood, fodder, grasses, leaf litter, etc.) was intensively explored for higher fungi both ascomycetous and basidiomycetous species.

\section{Collection and identification}

The area was surveyed in October 25 to 26, 2014. Altogether 33 species of fungal species, including both Ascomycetes (3 species) and Basidiomycetes fungi (30 species), were collected from the study area. The species collected were well dried in

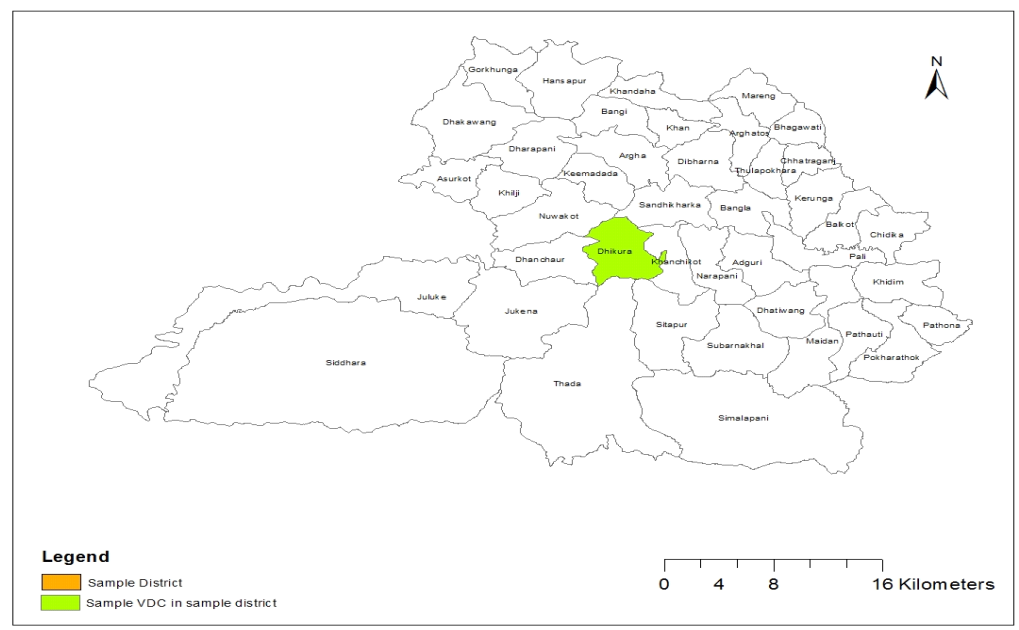

Fig. 1. Map of the study area

Terminalia chebula, Machillus odoratissima, Euphorbia royleana, Bambusa nepalensis, Ficus hispida, Sapium insigne, Ficus auriculata, Arundinella nepalensis, etc.

The climate of the study area is tropical to subtropical type with a fresh and humid climate. The average maximum temperature of Arghakhanchi is $28^{\circ} \mathrm{C}$ and a minimum of $4.5^{\circ} \mathrm{C}$. It receives an average annual rainfall of about 850 $\mathrm{mm}$ recorded at Khanchikot $\left(27^{\circ} 56^{\prime} \mathrm{N}, 83^{\circ} 09^{\prime} \mathrm{E}\right.$, 1,760 msl ) (Source: Department of Hydrology and Meteorology/GoN, 2005). Dhikura village lies at the central part of the Arghakhanchi district. It lies in the mid-hill zone. Dhikura village (divided into lower and upper Sursing village, 950-1,100 $\mathrm{msl}$ ) and adjoining Rotepakho Community Forest the shade and packed in paper envelops with proper tag/collection numbers. They are housed in National Herbarium and Plant Laboratories (KATH), Godawari, Lalitpur.

The fungi were brought to National Herbarium and Plant Laboratories (KATH), Godawari for identification, and making herbarium specimens. The identification was done following relevant literatures (Teng 1939; Walting 1973, Alexopoulous \& Mims, 1979; Dickson \& Lucas 1979; Pacioni, 1981, Dennis1981; Svréek 1983; Miller 1984; Purkayastha \& Chandra, 1985; Adhikari 2014). The nomenclature of all the identified fungal species follows Adhikari (2012, 2014). 


\section{Enumeration of species}

1. Coprinellus micaceus (Bull.: Fr.) Vil., Hop. \& John. [Agaricales: Psathyrellaceae]

Moist soil, Dhikura village- upper Sursing, 1,050 m, 26 October 2014; collection no. 425 , collector- RA

2. Daldinia concentrica (Bolt.: Fr.) Ces. \& De Not. [Xylariales: Xylariaceae]

Log of Litsea monopetala (Roxb.) Pers., Dhikura village- upper Sursing, 1,100 m, 25 October 2014, collection no. 410, collectorRA

3. Exobasidium butleri P. \& H. Sydow [Exobasidiales: Exobasidiaceae]

Green leaf of Rhododendron arboreum Sm., Dhikura village- upper Sursing, 1,100 m, 26 October 2014, collection no. 436, collectorRA

4. Exobasidium ovalifoliae $\mathrm{Li} \&$ Guo [Exobasidiales: Exobasidiaceae]

Green leaf margin of Schima wallichii Choisy, Rotepakho community forest, $950 \mathrm{~m}, 26$ October 2014, collection no. 442, collectorRA

5. Favolus sp. [Polyporales: Polyporaceae]

Log of Litsea monopetala (Roxb.) Pers., Dhikura village- upper Sursing, 1,050 m, 26 October 2014, collection no. 435, collectorRA

6. Fomes sp. [Polyporales: Polyporaceae]

The stump of Erythrina stricta Roxb., Dhikura village- upper Sursing, 1,050 m, 26 October 2014, collection no. 426, collectorRA

7. Ganoderma applanatum (Pers.) Pat. [Polyporales: Ganodermataceae]

Log of Terminalia bellirica (Gaertn.) Roxb., Rotepakho community forest, $950 \mathrm{~m}, 26$ October 2014, collection no. 427, collectorRA

8. Heterobasidium annosum (Fr.) Bref. [Russulales: Bonderzewiaceae]

The dead part of the trunk of the live tree of Machillus odoratissima Nees in Wall, Dhikura village- upper Sursing, 1,100 m, 25
October 2014, collection no. 402, collectorRA

9. Hexagonia sp. [Polyporales: Polyporaceae] The stump of Wendlandia coriacea (Wall.) DC., collection no. 413; Log of Shorea robusta Gaertn., collection no. 441, Dhikura village- upper Sursing, 1,100 m, 25 October 2014, collector- RA

10. Inonotus hispidus (Bull.: Fr.) Karst. [Hymenochaetales: Hymenochaetaceae]

The trunk of dead Machillus odoratissima Nees in Wall, Dhikura village- upperSursing, 1,050 m, 26 October 2014, collection no. 430, collector- RA

11. Ischnoderma sp. [Polyporales:

Fomitopsidaceae]

Fallen log of Castanopsis indica (J. Roxb. ex Lindl.) A. DC., Rotepakho community forest, $1,050 \mathrm{~m}, 26$ October 2014, collection no. 421, collector- RA

12. Lentinus conchatus (Bull.: Fr.) Schroet. [Polyporales: Polyporaceae]

Log of Ficus hispida L. f., Rotepakho community forest, $950 \mathrm{~m}, 26$ October 2014, collection no. 418 , collector- RA

13. Lycoperdon sp. [Agaricales: Lycoperdaceae] Moist soil, Rotepakho community forest, 950 m, 26 October 2014, collection no. 417, collector- RA

14. Microporous xanthopus (Fr.) Kuntz. [Polyporales: Polyporaceae]

Fallen branch of Terminalia bellirica (Gaertn.) Roxb., Dhikura village- lower Sursing, 900 m, 25 October 2014, collection no. 414, collector- RA

15. Morchella esculenta (L.: Fr.) Pers [Pezizales: Morchellaceae]

Moist soil, Rotepakho community forest, under mixed pine forest, $900 \mathrm{~m}, 25$ October 2014, collection no. 415, collector- RA

16. Panaeolus sp. [Agaricales: Bolbitaceae]

Log of Pinus roxburghii Sargent, Dhikura village- lower Sursing, 950 m, 26 October 2014, collection no. 446, collector- RA 
17. Phellinus gilvus (Schw.) Pat. [Hymenochaetales: Hymenochaetaceae]

Log of Grewia asiatica L., Dhikura villageupper Sursing, 1,100 m, 25 October 2014, collection no. 401 , collector- RA

18. Phellinus sp. [Hymenochaetales: Hymenochaetaceae]

The trunk of dead Terminalia chebula Retz., Dhikura village- upper Sursing, 1,050 m, 26 October 2014, collection no. 422, collectorRA

19. Pleurotopsis sp. [Agaricales: Pleurotaceae]

Log of Litsea monopetala (Roxb.) Pers., Dhikura village- upper Sursing, 1,100 m, 25 October 2014, collection no. 408, collectorRA

20. Polyporus sp. [Polyporales: Polyporaceae]

The stump of Grewia asiatica L., Dhikura village- upper Sursing, 1,100 m, 25 October 2014, collection no. 403, collector- RA

21. Polyporus sp. [Polyporales: Polyporaceae]

Log of Euphorbia royleana Boiss., Dhikura village- upper Sursing, 26 October 2014, collection no. 444 , collector- RA

22. Pseudohydnum gelatinosum (Scop.: Fr.) P. Karst. [Auriculariales: Auriculariaceae]

Log of Wendlandia coriacea (Wall.) DC., Dhikura village- upper Sursing, 1,050 m, 26 October 2014, collection no. 419, collectorRA

23. Radulomyces copelandii (Pat.) Hjorstam \& Spooner [Agaricales : Pterulaceae]

Fallen log of Terminalia chebula Retz., Rotepakho community forest, $950 \mathrm{~m}, 26$ October 2014, collection no. 423, collectorR A

24. Schizophyllum commune (Fr.) Fr. [Agaricales: Schizophyllaceae]

Rotten log of Sapium insigne (Royle) Benth. $\&$ Hook. f., Dhikura village- lower Sursing, 950 m, 25 October 2014, collection no. 407, collector- RA

25. Scleroderma citrinum Pers.: Pers. [Boletales: Sclerodermataceae]
Moist soil, Rotepakho community forest, under mixed pine forest, $950 \mathrm{~m}, 26$ October 2014, collection no. 417, collector- RA

26. Scleroderma sp. [Boletales:

Sclerodermataceae]

Moist soil, Dhikura village- upper Sursing, 1,000 m, 25 October 2014, collection no. 409, collector- RA

27. Stereum sp. [Russulales: Steriaceae]

The stump of Shorea robusta Gaertn., Dhikura village- lower Sursing, 950 m, 25 October 2014, collection no. 404, collector- RA

28. Suillus sp. [Boletales: Suillaceae]

Moist soil, Rotepakho community forest, under mixed pine forest, $950 \mathrm{~m}, 26$ October 2014, collection no. 416, collector- RA

29. Trametes hirsuta (Fr.) Pilat. [Polyporales: Polyporaceae]

The stump of a tree, Rotepakho community forest, $900 \mathrm{~m}, 26$ October 2014, collection no. 428, collector- RA

30. Tremella fusiformis Berk. [Tremellales: Tremellaceae]

Log of Ficus auriculata Lour., Dhikura village- upper Sursing, 1,050 m, 26 October 2014, collection no. 424, collector- RA

31. Trichoglossum hirsutum (Pers.: Fr.) Boud. [Leotiales: Leotiaceae]

Moist soil, Rotepakho community forest, 950 m, 25 October 2014, collection no. 412, collector- RA

32. Xylobolus spectabilis (Klotz.) Boiden [Russulales: Stereaceae]

The trunk of dead Bambusa nepalensis Stapleton, Dhikura village- upper Sursing, $1,080 \mathrm{~m}, 25$ October 2014, collection no. 405, collector- RA

\section{Results and Discussion}

Altogether 33 species of fungi, including Ascomycetes (3 species) and Basidiomycetes (30 species), were collected from the study area. Out of total 33 identified fungal species, Ascomycetes species were from three orders belonging to three families and three genera, whereas Basidiomycetes 
species were from eight orders belonging to 17 families and 26 genera.

The distribution of macro-fungal species is low in the hot and dry season, and so during autumn. The collected species of Ascomycetes fungi were the member of three different orders: Leotiales, Pezizales \& Xylariales with their corresponding family Leotiaceae, Morchellaceae and Xylariaceae respectively (see in the enumeration of mushroom species). In contrast, most of the collected Basidiomycetes fungi were the members of order Polyporales. Polyporales, the dominant order, in the study area with 11 species was followed by Agaricales (6 species), Boletales, Hymenochaetales, Russulales (3 species each) (Figure 2). Similarly, Polyporaceae was found to be the dominant family represented by nine species. It was followed by Hymenochaetaceae (3 species) and equally followed by Exobasidiaceae, Sclerodermataceae, Stereaceae (2 species each), and the rest of the families were represented by only single Basidiomycetes species (Figure 3).

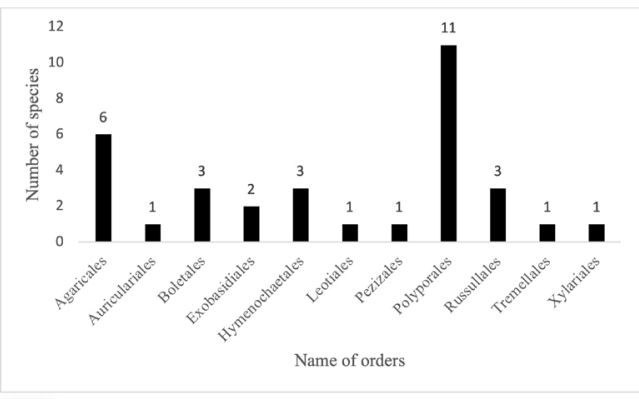

Fig. 2. Orders representing the number of species in the study area

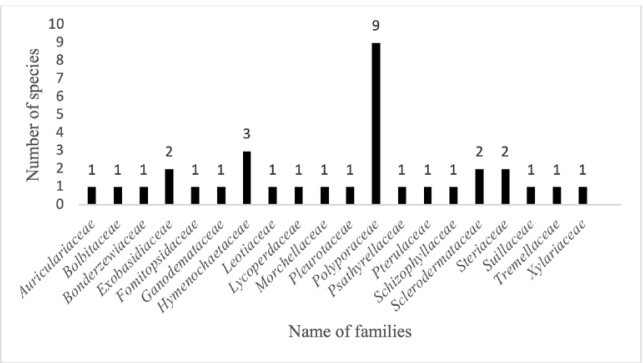

Fig. 3. Families representing the number of species in the study area

Basidiomycetes species, especially polypores, were the most common and were found to grow on dead woods, fallen logs, stumps, rotten branches, but Fomes sp., Heterobasidion annosum, etc. were found on dead branches of trees and trunks of living trees. Out of 33 fungal species, Basidiomycetes species like Lycoperdon sp., Microporus xanthopus, Ganoderma applanatum were found to be very common in the study area. Species of Ganoderma, Scleroderma citrinum, and Trametes hirsuta are reported in the present study area was also reported by Aryal \& Budhathoki (2013) at Sankarnagar community forest, Rupandehi district (Central Nepal).

\section{Conclusion}

A total of 33 fungal species from Ascomycetes (3 species) and Basidiomycetes fungi (30 species) were collected from the Dhikura village and its adjoining Rotepakho community forest, Arghakhanchi district, Central Nepal. The identified Ascomycetes species were from three orders belonging to three families and three genera, whereas Basidiomycetes species were from eight orders belonging to 17 families and 26 genera. In overall, Polyporales and Polyporaceae were the dominant order and family, respectively. Litsea monopetala was found to be the primary host plant for three different mushroom species (including one Ascomycetes and two Basidiomycetes species).

\section{Acknowledgments}

The author would like to express gratitude to Mr. Subhash Khatri, Chief, National Herbarium and Plant Laboratories, Godawari, Lalitpur for encouragement and Dr. Mahesh Kumar Adhikari (senior mycologist), Secretary, Nepal Academy of Science and Technology Khumaltar, Lalitpur for suggestions and co-operation in the identification of fungal species. I gratefully acknowledge Mr. Gaurav Parmar, Ph.D. scholar, Chinese Academy of Sciences, Beijing, China, for his valuable comments and suggestions.

\section{References}

Adhikari, M. K. 1994-95. Mycodiversity in Nepal: a glimpse. Bull. Nat. Hist. Soc. Nep. 3-4 (1-4):4-6.

Adhikari, M.K. 1999. Status of wild potential mushrooms in Nepal. Pp.1339-1350. In: Proceedings of III ${ }^{\text {d }}$ National Conference on Science and Technology March 8-11, 1999. Nepal Academy of 
Science and Technology, Kathmandu, Nepal.

Adhikari, M. K. 2000. Status and conservation of fungi in Nepal. Journal of Natural History Museum 19: $117-133$.

Adhikari, M.K. 2009. Researches on the Nepalese mycoflora: revised account on the history of mycological explorations. Published by K.S. Adhikari, Kathmandu, Nepal.

Adhikari, M.K. 2012. Researches on the Nepalese mycoflora-2: checklist of macrofungi (mushrooms). Published by K.S. Adhikari, Kathmandu, Nepal.

Adhikari, M.K. 2014a. Mushrooms of Nepal. (Eds. G. Durrieu and H.V.T.Cotter,). Published by K.S . Adhikari, GPO Box no. 21758, Kathmandu, Nepal.

Adhikari, M. K. 2014b. Addition and correction to the knowledge on edibility of wild mushrooms in Nepal: a discussion. Bulletin of the Department of Plant Resources 36:1-15.

Adhikari, M.K. 2014c. The status of collection and utilization of Nepalese Mycobiota. Pp.13-18. In: Proceedings of the seminar in mushroom consumption and poisoning risk held at $14^{\text {th }}$ January 2014. (Ed. Raut, J.K.). Nepal Academy of Science and Technology, Khumaltar, Lalitpur, Nepal.

Adhikari, M.K. and Bhattarai, K. R. 2014. Catalogue of fungi preserved in National Herbarium and Plant Laboratories (KATH), Mycology section, Godavary. Department of Plant resources, National Herbarium and Plant Laboratories, Godawari, Lalitpur, Nepal. 107p +viii photoplate. Alexopoulos, C.J. and Mims C.W. 1979. Introductory Mycology. John Willey and Sons, Inc. New York. USA.

Alexopoulos, J.C. and Beneke, E.S. 1962. Laboratory Manual for Introductory Mycology. Burgess Publishing Company, USA.

Aryal, H. P. and Budhathoki, U. 2013. Mycodiversity at Sankarnagar community for e s t, Rupandehi district. Nepal Journal of Science and Technology 14(1):75-80.
Berkely, M. J. 1838. Description of exotic fungi in the collection of Sir W.J. Hooker from memories and notes of J.F. Hooker from memories and notes of J.F. Klotsch with addition and correction. Ans. Natural History 3:375-401.

Bhusal, M., Panday, H.L., Sharma, S.L., Bhandari, H. and Aryal, K.P. (eds.). 2013. District and VDC Profile of Nepal-2013. Intensive study and Research Center Pvt. Ltd., Kathmandu, Nepal.

Dennis, R.W.G. 1981. Common British Fungi. Saiga Publishing Co. Ltd., England.

Dickson, C. and Lucas, J. 1979. The Encyclopedia of Mushrooms. Orbis Publishing Limited, London.

Gold, T.C. 1975. The Biology of Fungi. The English language Book Society and Hutchinson of London. Hutchinson and Co- (Publishers) Ltd., India.

Lloyd, C. G. 1808. Mycological notes. no. 1:75. Lloyd Library \& Museum, Cincinnati, Ohio, USA.

Miller, O.K. Jr. 1984. Mushrooms of North America. Published by E.P. Dutton, a Division of Elsevier-Dutton Publishing company, New York, USA.

Pacioni, G. 1981. Simon \& Schuster's Guide to Mushrooms. (Ed. Lincoff, G.). Simon \& Schuster Inc., USA.

Purkayastha, R. P. and Chandra, A. 1985. Manual of Indian Edible Mushrooms. Today's and

Tomorrow's Printers and Publishers, New Delhi, India.

Svrček, M. 1983. The Hamlyn Book of Mushrooms and Fungi. The Hamlyn Publishing Group Limited, Artia, Prague, Czechoslovakia.

Teng, S.C. 1939. Higher Fungi of China. National Institute of Zoology and Botany, Academia Sinica, China.

Walting, R. 1973. Identification of the Larger Fungi. Hulton Educational Publications Ltd. Raans Road, Amersham, Bucks, London. 